\title{
The development of a new instrument to assess metacognitive strategy knowledge about academic writing and its relation to self-regulated writing and writing performance
}

\author{
Yves Karlen \\ University of Zurich, Zurich | Switzerland
}

\begin{abstract}
Writing is a complex, recursive, and strategic process that requires metacognitive competencies. Skillful writers have a high level of metacognitive strategy knowledge (MSK) and use strategies effectively. MSK about writing describes a person's verbalizable knowledge and awareness of memory, comprehension, and higher order processes that underlie skillful writing. Measurement instruments assessing students' MSK about academic writing in higher education that can be used for group settings and large samples are lacking. The aim of this article is to describe the development of a new MSK test instrument. The MSK test consists of three different writing scenarios related to the three self-regulated writing phases: planning prior to composing full text, monitoring the writing during composition, and subsequent revision. The findings of a pre-study ( $N=51)$ and two studies $(N=23 ; N=113)$ showed that the new MSK test is economical in use, is reliable and has high content validity. Further, the findings demonstrated external validity of the new instrument in terms of relationships with students' metacognitive strategy use and writing performance. Implications for future research and educational practice are discussed.
\end{abstract}

Keywords: Metacognition, Metacognitive strategy knowledge, Academic writing, Assessment

\section{> journal of WRITING RESEARCH}

Karlen, Y. (2017). The development of a new instrument to assess metacognitive strategy knowledge about academic writing and its relation to self-regulated writing and writing performance. Journal of Writing Research,9(1), 61-86. doi:10.17239/jowr-2017.09.01.03

Contact: Yves Karlen, University of Zurich / Institute of Education, Freiestrasse 36, Zurich, 8032 Switzerland - ykarlen@ife.uzh.ch

Copyright: Earli | This article is published under Creative Commons Attribution-NoncommercialNo Derivative Works 3.0 Unported license. 


\section{Introduction}

Academic writing plays an important role in higher education and in academic life. Writing is highly demanding, as it is a complex recursive process that not only involves the writer's knowledge of grammar, genre, and vocabulary but also requires metacognitive competencies (Graham \& Harris, 2000). Academic writing is a selfplanned, self-initiated, self-regulated, metacognitive process (Hayes, 1996; Zimmerman \& Risemberg, 1997). For example, writers have to prepare and plan what and how to write, monitor their draft writing process, and evaluate and revise what they have written. Further, they have to choose and apply effective strategies in order to process information, regulate their motivation and attention to stay focused, and supervise their writing processes. The research literature has shown that skilled writers have a rich understanding of the characteristics of high-quality compositions, high-level knowledge about the higher order processes of writing, and knowledge about the use of effective strategies (Lin, Monroe, \& Troia, 2007; McCutchen, 2006). Writing demands the use of metacognitive knowledge and skills to successfully monitor and regulate the whole writing process (Hacker, Keener, \& Kircher, 2009). In line with these insights, several studies have demonstrated the impact of metacognition on successful writing (e.g., Harris, Santangelo, \& Graham, 2010; Saddler \& Graham, 2007). To understand why some writers self-regulate their writing process successfully and others unsuccessfully, it can be helpful to take a closer look at their metacognitive strategy knowledge (MSK) about the writing process. Empirical results showed that MSK plays an important role in writing development and achievement (Lin et al., 2007; McCutchen, 2006). In this study, we use a new approach to assess writer's MSK about academic writing in higher education. The aim of this study is to develop a new economical, reliable, and valid instrument to assess students' MSK about academic writing. An instrument of this kind could be used as a diagnostic measure for teachers, for example, or as a tool for researchers interested in the relationship between MSK about academic writing and other variables.

\subsection{Metacognition}

Metacognition is broadly understood as cognition about one's cognition (Flavell, Miller, \& Miller, 2002). Although the literature mentions several distinct models of metacognition (Brown, 1987; Paris \& Winograd, 1990; Schraw \& Moshman, 1995), they all have one feature in common - namely, that metacognition is divided into a knowledge component and a regulation component. The knowledge component of metacognition refers to verbalizable knowledge about comprehension, memory, and learning processes. Following Flavell (1979), metacognitive knowledge can be divided into knowledge about persons, tasks, and strategies. Knowledge about persons includes knowledge about the strengths and weakness of a person's own memory and information processing competencies. Knowledge about tasks involves knowledge 


\section{3 | JOURNAL OF WRITING RESEARCH}

about specific task characteristics and about how task-related learning goals can be achieved. Knowledge about strategies involves knowledge about strategy characteristics. Paris, Lipson, and Wixson (1983) further divided strategy knowledge into three subcomponents that represent different representation levels: Declarative strategy knowledge is knowledge about what strategies are. Procedural strategy knowledge is knowledge about how strategies should be applied. Conditional strategy knowledge is knowledge about when and why specific strategies are useful. In addition, Borkowski and Turner's (1990) metamemory model used three different terms (specific, relational, and general metacognitive strategy knowledge) to describe different generalization levels of the knowledge components of metacognition: Specific strategy knowledge refers to knowledge about the specific characteristics of individual strategies. Relational strategy knowledge includes the processes that refer to the awareness of differences and similarities between strategies. General strategy knowledge includes a general understanding of strategy use and its significance for the cognitive processes.

In this study, the term metacognitive strategy knowledge (MSK) is used to refer to conditional and relational strategy knowledge. MSK is defined as verbalizable knowledge about disadvantages and advantages of specific strategies regarding task characteristics. MSK includes knowledge about why and when those strategies should be used to complete a task successfully. Skillful writing underlies several higher order processes (e.g., planning, revising, choosing and using strategies successfully); it requires writers to have MSK about those higher order processes to successfully manage the writing process. More specifically, MSK enables writers to critically consider a specific writing task, determine what strategies will be best to achieve the goals for that specific task, and identify why and when which strategy should be applied for successful task fulfillment. MSK helps writers to plan, produce, and revise a text (Harris et al., 2010). In contrast, struggling writers often lack this knowledge of what constitutes successful regulation of processes writing. MSK is an important link between individuals' self-regulation of the writing process and writing achievement.

The regulation component of metacognition refers to procedural aspects of metacognition; this involves monitoring and regulating processes of cognitive, metacognitive, and behavioral activities (Nelson \& Narens, 1994). Procedural aspects of metacognition help students to actively control, coordinate, and regulate their learning process. Furthermore, regulation of one's cognitive activities can be divided into three subcomponents: planning, monitoring, and evaluating processes (Brown, 1987; Veenman, Hout-Wolters, \& Afflerbach, 2006). Planning activities (e.g., decisions about what is to be done and how to proceed; setting learning goals) are performed before the actual gathering of information or the actual writing process starts. Monitoring activities are performed during the learning and writing process. Students may use monitoring actives (e.g., self-questioning) to determine whether they are on track to reach a set standard. Evaluation activities are performed after the learning and writing process; students evaluate their learning results and the strategies used in order 
to determine whether their plan worked or whether they should change their approach (Veenman et al., 2006). Students that actively monitor and evaluate their learning processes are more aware of when and how they have to adapt their strategic behavior (Nelson \& Narens, 1994). Overall, engaging in metacognitive processes is a salient feature of effective self-regulated writing (Harris et al., 2010).

\subsection{Metacognition and self-regulated writing}

Successfully monitoring and regulating one's own writing process is a main feature of effective self-regulated academic writing (Hacker et al., 2009; Zimmerman \& Risemberg, 1997). Skillful writers have a rich understanding of the essential characteristics of high-quality composing as well as knowledge about the higher order processes that allow successful regulation of the writing process. In an early study, Graham, Schwartz, and MacArthur (1993) found that regular high school students had more elaborated MSK than students with learning disabilities did. Conversely, students with learning disabilities showed less accurate strategy use than regular students. In another early study, Ferrari, Bouffard, and Rainville (1998) found that good writers relied more on MSK and metacognitive skills than poor writers. Good writers waited longer before beginning to write and evaluated the structure of their text more accurately than poor writers. In line with this result, Beauvais, Olive, and Passerault (2011) showed that good writers tailor their writing behavior to match the type of text and achieve high quality writing. Lin et al. (2007) used interviews to assess the MSK of writers in Grades 2 to 8. They found significant differences in MSK across grades and writing levels. Older students showed higher MSK than younger students did, and skillful writers showed higher MSK than less skilled writers. Saddler and Graham (2007) found similar results for students in Grade 4: Skilled writers had more MSK than less skilled writers, and individual differences in MSK were related to the differences in writing performance. In line with that, Olinghouse and Graham (2009) found for even younger students (in Grade 2 and Grade 4) a positive correlation between planning the writing, MSK, and writing performance. As expected, students in Grade 4 possessed greater knowledge about the role of substantive processes, higher motivation, and abilities in writing than students in Grade 2. Negretti (2012) conducted a longitudinal study with college students. To activate their MSK about their writing process, the students had to fill out standardized learning journals containing specific questions about their writing. The results showed a relationship between students' MSK, task perception, and the quality of their evaluation of their writing. Further, students' MSK was associated with their self-regulation of their writing process and the development of individual writing approaches. Therefore, MSK might be seen as an important prerequisite of strategy use (Karlen, 2015). Based on Program for International Student Assessment (PISA) 2009 data, Artelt and Schneider (2015) examined the relationship between MSK, strategy use, and reading competence for 34 Organization for Economic Co-operation and Development (OECD) countries. For most of the countries, MSK had 


\section{5 | JOURNAL OF WRITING RESEARCH}

a positive effect on reading competence via the use of strategies, and there was a significant effect of strategy use as mediator. It can be expected that similar results can be found for the context of writing. In sum, studies have found that (1) skillful writers have more MSK than struggling writers, (2) writers' metacognitive competencies are positively associated with their writing achievement, and (3) writers with high MSK show more appropriate strategy use than writers with lower MSK. Therefore, individual differences in metacognitive competencies play an important role in explaining individual differences in writing.

\subsection{Assessing metacognitive strategy knowledge}

Researchers have developed different instruments to assess MSK. Questionnaires (Schraw \& Dennison, 1994), interviews (Kreutzer, Leonard, \& Flavell, 1975), or thinkaloud protocols (Swanson, 1990) are prominently used. In the context of writing, interviews or open-ended questions (Englert, Raphael, Fear, \& Anderson, 1988; Graham, Schwartz, \& MacArthur, 1993) and standardized questionnaires (Hammann, 2005) are common instruments to assess MSK. Wirth and Leutner (2008) grouped the different measurement methods according to two standards: Instruments with a quantitative standard (i.e., questionnaires) follow the idea that a maximum view (e.g., high frequency of strategy use) represents the optimal way of regulating ones' learning or writing. In writing, an optimum view - which stresses not 'the more the better' but rather 'the better the fit... the better' (e.g., having knowledge about under what conditions specific strategies are useful for a specific writing task) - could be more appropriate. Measurement methods based on this optimum view follow a qualitative standard. Scenario-based instruments, called MSK tests, belong to this group. They consist of several scenarios that are related to a specific domain (e.g., reading). Each scenario includes a list of multiple items (strategy options) that vary in their degree of usefulness. In MSK tests, participants must identify the task-specific characteristics and goals and activate their knowledge about the attributes of the presented strategies in order to appropriately rate the usefulness of each strategy in view of task demands. The MSK score is not evaluated based on the direct rating of one specific strategy (item) but on the relative estimated relation between two strategies (= pair comparison; e.g., strategy $X$ is more useful than strategy $Y$ ). The definition of the evaluation standards is based on experts' judgment. Experts from the specific field also rate the usefulness of all presented strategies. Pair comparisons are used to determine the average agreement of the experts about the superiority or inferiority of one strategy compared to another strategy. The paired comparisons serve as a qualitative standard and offer a clear benchmark for students' answers. The correspondence between students' relative rating of these pair comparisons and the experts' rating of these pair comparisons is expressed in a score that indicates the extent of the student's MSK. The higher the correspondence between the student's and the experts' rating, the higher the student's MSK score. Several researchers have found that these tests are economical in use and show high 
reliability and validity (Händel, Artelt, \& Weinert, 2013; Maag Merki, Ramseier, \& Karlen, 2013). Moreover, these tests refer to specific learning scenarios; this allows measurement of task- or domain-specific MSK. The tests have been developed for several domains (e.g., mathematics, reading, scientific discovery learning) and schooling levels (from kindergarten to upper secondary school level), and for students with special needs (Artelt, Neuenhaus, Lingel, \& Schneider, 2012; Händel, Lockl, Heydrich, Weinert, \& Artelt, 2014; Karlen, Maag Merki, \& Ramseier, 2014). However, the results of these domain- or task-specific tests cannot be transferred as they are to other domains, as Neuenhaus, Artelt, Lingel, and Schneider (2010) found that MSK is to a certain degree domain-specific or at least restricted to the learning scenarios being assessed. Moreover, MSK tests for university students are still lacking. And no MSK test that focuses on academic writing is available. The aim of this study is therefore to develop a new scenario-based MSK test that assesses students' MSK about academic writing in an economical, reliable, and valid manner.

\section{The present research}

\subsection{Purpose and research question}

This paper describes the development of a new MSK test. More precisely, it explores the extent to which this new test shows adequate reliability (internal consistency) and content and external validity. To achieve this goal, the present research includes data and results from several studies. In a pre-study with a sample of students, we developed the first draft of the MSK test, with three writing scenarios that each included a list of different strategies. The aim of this pre-study with open-ended questions was to identify several strategies that vary in their degree of usefulness and represent students' selfregulated writing behavior as accurately as possible. The aim of Study 1 was to establish a clear external benchmark for the estimation of the MSK test score. To this end, a sample of experts that included linguists and scientists in the field of academic writing and learning strategies were asked to rate the usefulness of all listed strategies. In Study 2, the external validity of the MSK test was explored by means of correlation with students' self-reported metacognitive strategy use and writing performance.

\subsection{Pre-study: Construction of the metacognitive strategy knowledge test}

Based on theoretical models of self-regulated writing (Hayes, 1996; Zimmerman \& Risemberg, 1997), a new MSK test with three different writing scenarios was developed in a pre-study. Three scenarios are allocated to the three phases of self-regulated writing: (1) finding an idea prior to composing full text, (2) monitoring the writing during composition, and (3) evaluating the writing process (see Table 1). The fact that 


\section{7 | JOURNAL OF WRITING RESEARCH}

all three phases of the academic writing process are taken into consideration contributes to the content validity of the test.

For each writing scenario, different strategies that vary in their degree of usefulness for the specific requirements of the scenario needed to be listed. To increase the content validity of the test and to have a list of strategies that are as close as possible to students' actual strategic behavior, a pre-study was conducted with 51 students (Age: $M$ $=26$ years, $\mathrm{SD}=6.82$ ) studying at a university in Switzerland. The students were recruited from two different courses in education degree programs at the university; $52 \%$ of the participants were in the bachelor's degree program, and the other $48 \%$ were in the master's degree program. The students had to answer three open-ended questions and describe as accurately as possible how they proceed in these specific writing situations. The first question ('What do you do before you start writing an academic paper?') aimed to identify students' strategic behavior before starting to write an academic paper. The second question ('What do you do to stay on track while writing your academic paper?') aimed to assess students' strategy use during the writing process. The third question ('How do you proceed when you revise your academic paper?') focused on students' strategy use while revising their academic paper in the post-action phase. All open-ended answers were coded using a coding scheme that was created on the basis of existing strategy taxonomies (e.g., Pintrich, Smith, Garcia, \& McKeachie, 1993) and continuously expanded based on the empirical data in an iterative process. This approach was used to represent students' self-reported strategies as accurately as possible and to provide a broad range of different strategies. Students' open-ended answers were condensed into short strategy statements. This procedure made it possible to identify different strategies that show a strong relationship to students' writing approach. Finally, for a first draft of the MSK test, 27 strategies were chosen that differ from a theoretical point of view in their degree of usefulness regarding the scenarios' specific challenges.

Table 1. Structure of the Metacognitive Strategy Knowledge Test on Self-Regulated Academic Writing and Item Examples

\begin{tabular}{|c|c|c|}
\hline Writing phase & Writing situation & Example item \\
\hline Pre-action & $\begin{array}{l}\text { Proceeding in the stage } \\
\text { before writing }\end{array}$ & $\begin{array}{l}\text { She looks for a topic on which a lot of research } \\
\text { has been conducted, so that she has sufficient } \\
\text { material to complete the assignment. }\end{array}$ \\
\hline Action & $\begin{array}{l}\text { Monitoring the work } \\
\text { process while writing }\end{array}$ & $\begin{array}{l}\text { While writing, she occasionally reads a portion of } \\
\text { the text out loud to check for comprehensibility. }\end{array}$ \\
\hline Post-action & Revising the paper & $\begin{array}{l}\text { She checks and revises her sentences as she goes } \\
\text { along and at the same time pays attention to } \\
\text { improving content and style/grammar. }\end{array}$ \\
\hline
\end{tabular}




\section{Study 1: Experts rating}

In scenario-based MSK tests with a list of multiple items (e.g., Händel et al., 2013; Maag Merki et al., 2013), items are scored via pair comparison (two strategies, with one strategy as superior or subordinate to the other strategy). This means that it is not the direct rating of one strategy (item) that is significant but rather the indirectly estimated relation between two strategies (pair comparison). To define the validity of the direction of the pair comparisons (e.g., strategy $\mathrm{X}$ is more appropriate than strategy $\mathrm{Y}$ ) and to ensure further content validity, experts were asked to provide their judgments. This allows analysis of the validity of the theoretical assembled pairs of strategies and makes it possible to obtain a clear benchmark to build the MSK score. Therefore, the aim of this study was to establish further content validity of the MSK test through expert ratings and hence, to develop an objective scoring procedure. Further, expert comments and feedback on the MSK test were used to optimize the length of the test with the aim to have an instrument that is as economical in use as possible.

\subsection{Method}

\subsubsection{Participants and procedures}

A sample of experts that included linguists and scientists in the field of academic writing and learning strategies were asked to fill out the MSK test and to rate the usefulness of each strategy compared to the other strategies for the specific writing situation. Overall, $N=23$ experts from several universities and countries volunteered and provided their judgments. After each writing scenario, the experts could add comments or recommendations for improvement of the test instrument. It took the experts an average of $5.05 \mathrm{~min}(\mathrm{SD}=0.45)$ to complete the first version of this new MSK test.

\subsubsection{Measure: Metacognitive strategy knowledge test}

Based on theoretical pre-work and the results of the pre-study, a version of the MSK test with three different writing scenarios and a list of 27 different strategies in total was used. Each of the three scenarios included a list of nine strategies that theoretically varied in their degree of effectiveness. All strategies listed were rated on 6-point Likert scale from 1 (is not useful at all) to 6 (is very useful).

\subsection{Results and discussion}

In a first step, expert comments and feedback on the MSK test were used to optimize the MSK test. Based on these comments and feedback, seven strategies were removed, which is why the final version of the MSK test includes a list of 20 strategies and not 27. In a second step, for each of the theory-based pair comparison, the relative degree of agreement among the experts was evaluated. Experts' answers were processed in that for each pair comparison, agreement on the superiority or inferiority of one strategy 
69 | JOURNAL OF WRITING RESEARCH

relative to the other strategy was evaluated (e.g., strategy $X$ is more useful than strategy Y). The estimation of average percentage of agreement is an appropriate coefficient to determine agreement between several raters for dichotomous data (Wirtz \& Caspar, 2002). Following the established benchmark criterion of other MSK tests (Händel et al., 2014; Maag Merki et al., 2013), a pair comparison was assumed to be valid when at least $75 \%$ of the experts agreed on the relation between two strategies. This high level of agreement was relevant for achieving high content validity. If experts' agreement was lower than the criterion of $75 \%$ agreement for a specific pair comparison, then this pair comparison was considered to be invalid for the assessment of students' MSK. Figure 1 shows experts' agreement for each pair comparison. A value of 100 means that $100 \%$ of the experts agreed on the relation between two strategies. A value of 0 means that there was no agreement $(0 \%)$ between the experts on a strategy alternative being superior or inferior to another strategy for the specific writing situation. Asi Figure 1 shows, for 34 pair comparisons the experts agreed that a strategy alternative was superior to another strategy. Nine pair comparisons did not reach the criterion of at least $75 \%$ agreement and were therefore excluded. The three scenarios had a different number of valid pair comparisons. Scenario 1 had the highest number (17) of valid pair comparisons. For scenarios 2 and 3, eight and nine valid pair comparisons were available.

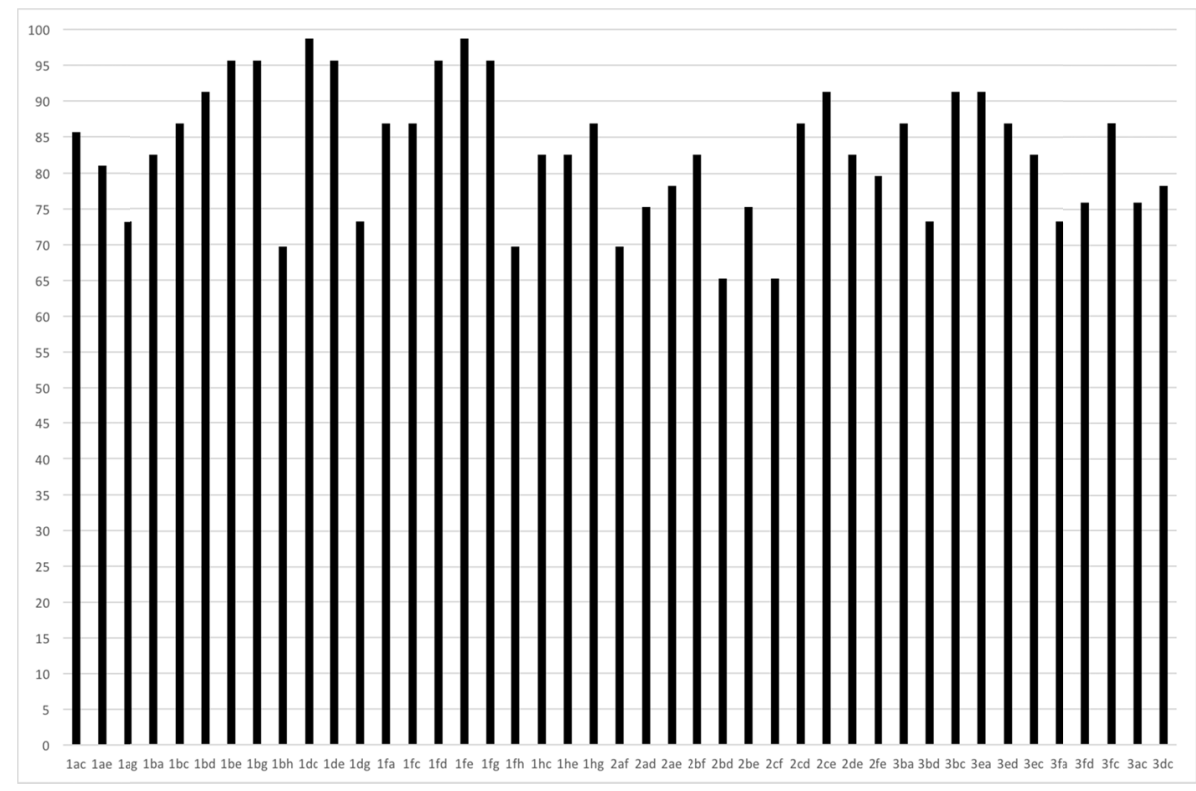

Figure 1. Agreement among the experts for each pair comparison. 
To summarize, this approach made it possible to establish a clear benchmark and evaluation standard for the estimation of the MSK test score. Thirty-four pair comparisons are available to estimate the MSK score. The high level of agreement among the experts contributes to high content validity of the new MSK test.

\section{Study 2: Evaluation of a new test instrument}

The aim of study 2 was to examine internal consistency and to analyze external validity of the MSK test by correlation analysis between the MSK test score and external measures (metacognitive strategy use and writing achievement). Based on previous findings (Hacker et al., 2009; Saddler \& Graham, 2007), it was expected that MSK about academic writing is positively related to writing performance (hypothesis 1). Theoretical and empirical literature showed that MSK and self-reported strategy use are moderately positively related to each other (Karlen, 2015). Therefore, we expected to find a positive moderate relationship between MSK and self-reported metacognitive strategy use (hypothesis 2). Finally, in the literature it is argued that MSK is a stronger predictor of achievement than self-reported frequency of strategy (e.g., Artelt \& Schneider, 2015; Maag Merki et al., 2013; Wirth \& Leutner, 2008). Therefore, we expected that MSK is a stronger predictor of achievement than self-reported metacognitive strategy use (hypothesis 3).

\subsection{Participants and procedures}

The participants, 113 students (Age: $M=26.00$ years, $S D=6.82$ ) at a university in Switzerland, filled out an online questionnaire. Students had to be in a degree program in education science and were therefore mainly women (82\%). On average, the students were in their third semester $(M=3.07, \mathrm{SD}=1.56)$ at the university. All students were given time to complete the online questionnaire during a class.

\subsection{Method}

\subsubsection{Metacognitive strategy knowledge about academic writing}

The newly developed MSK test had three different writing scenarios, all of which contained a list of several more-or-less useful strategies. Students had to rate all listed strategies according to their usefulness considering the requirements of the specific scenario on 6-point Likert-type scale ranging from 1 (not useful at all) to 6 (very useful). It was not the estimated usefulness of one single strategies that was evaluated but rather the student's relative estimation of the usefulness of one strategy compared to another strategy (i.e. pair comparison). To compute the MSK score, the student's relative estimation of a pair comparison was compared with the experts' relative estimation of pair comparisons. Students received a score of 1 if their judgment on a pair comparison was in line with the experts' rating of the pair comparison. If their judgment was not in 


\section{1 | JOURNAL OF WRITING RESEARCH}

line with the experts' ratings (e.g., contrary or two strategies being rated equal) students received zero points. The value of the MSK score varied between $0 \quad(0 \%$ correspondence with the experts, weak MSK) and 1 (100\% correspondence with the experts, high MSK). It took students on average $2.35 \mathrm{~min}(\mathrm{SD}=0.40)$ to fill out the MSK test.

\subsubsection{Self-reported strategy use}

Self-reported strategy use was assessed with three metacognitive sub-scales (planning, monitoring, evaluating) adapted from Kaplan, Lichtinger, and Gorodetsky (2009). Five planning strategies items (e.g., 'Before I start writing, I plan an outline of what I'll be writing about'), five monitoring strategies items (e.g., 'During writing, I check to see if what I am writing fits'), and four evaluation strategies items (e.g., 'After finishing writing a section or part of it, I think about whether what I have written is connected with what I wrote before') were used to measure metacognitive strategy use. The response scale for all items ranged from 1 (not true at all) to 4 (very true). All sub-scales showed appropriate Cronbach's alpha values (see Table 3).

\subsubsection{Achievement}

Students' writing achievement was assessed with a short academic writing task: Students had to write an academic paper with a length of 6 to 7 pages. The task consisted of formulating a research question, providing a theoretical framework, and answering the question using scientific literature. Students had to cite literature correctly and prepare an appropriate reference list. All of the academic papers were rated on defined criteria (i.e., formulation of the question, theory, structure, train of thought, selection of literature, citations, language). All papers were rated based on the Swiss grading system, which ranges from 1 (insufficient) to 6 (excellent).

\subsection{Results and discussion}

First, the psychometric properties of the newly developed MSK test were investigated. Therefore, the average item difficulty and item-total-correlation values were calculated for each pair comparison. Items with low item-difficulty ( $\mathrm{pl}>$.85) or item with very high item-difficulty $(\mathrm{pl}<.20)$ as well as items with negative item-total correlation values and lower item-total correlation values than rit $<.20$ (Ebel, 1979) were excluded, which resulted in a decrease of 14 item pairs. The final version of the MSK test included 20 pair comparisons. Table 2 shows mean, standard deviation, and item-total correlation values for each pair comparison. Overall, the item-total correlation values are appropriate. However, also pair comparisons with low item-total correlation values but higher than the benchmark of $r<.20$ were kept in to achieve a high variation of different strategies for each of the writing scenarios. To compute the MSK score, the mean value over all included pair comparison items was calculated. The mean value was $M=.62(S D=.21)$ for the sample investigated. It was possible for the range of scores 
to run from 0 to 1 , and this was used well; no ceiling or floor effects were found. The level of difficulty of the MSK test was therefore well attuned to the sample. The internal consistency of the MSK test was satisfactory $(\alpha=.77)$. This indicates that the new MSK test was internally reliable. The distribution of the MSK score was close to a normal distribution (skewness: -0.47; kurtosis -0.03).

Table 2. Means and standard deviations and item-total correlations for all pair comparisons

\begin{tabular}{|c|c|c|c|}
\hline Pair Comparison & $M$ & SD & $r_{i t}$ \\
\hline $1 \mathrm{ba}$ & .53 & .49 & .52 \\
\hline $1 \mathrm{be}$ & .81 & .38 & .30 \\
\hline $1 \mathrm{fa}$ & .62 & .49 & .34 \\
\hline $1 \mathrm{hc}$ & .61 & .48 & .44 \\
\hline 1 he & .68 & .47 & .54 \\
\hline $1 \mathrm{hg}$ & .61 & .49 & .30 \\
\hline $1 \mathrm{dc}$ & .64 & .48 & .44 \\
\hline $2 \mathrm{ae}$ & .70 & .46 & .48 \\
\hline 2 be & .52 & .50 & .55 \\
\hline 2ce & .61 & .49 & .60 \\
\hline $2 \mathrm{de}$ & .53 & .50 & .32 \\
\hline $2 \mathrm{fe}$ & .48 & .50 & .43 \\
\hline $2 \mathrm{~cd}$ & .47 & .50 & .21 \\
\hline $3 \mathrm{ba}$ & .56 & .49 & .22 \\
\hline $3 \mathrm{bc}$ & .78 & .41 & .25 \\
\hline 3 ea & .66 & .46 & .32 \\
\hline 3ed & .54 & .50 & .35 \\
\hline $3 e c$ & .89 & .29 & .20 \\
\hline $3 \mathrm{fc}$ & .76 & .43 & .24 \\
\hline $3 \mathrm{fd}$ & .55 & .49 & .23 \\
\hline
\end{tabular}

Note. $1-3=$ scenarios $1-3 ; \mathrm{a}-\mathrm{h}=$ strategies; rit = item-total correlation; possible range 0 to 1.

Second, the relation between MSK, self-reported planning, monitoring, and evaluation strategy use, and achievement was analyzed by correlation analyses. Table 3 presents the intercorrelations between all measured variables. As expected, MSK was positively correlated with all variables. Similar patterns were found for all correlations between MSK and planning, monitoring, and evaluation strategies. The higher the students' MSK was, the more that students reported using planning, monitoring, and evaluation strategies. Furthermore, MSK was positively correlated with achievement. Positive correlations were also found among planning, monitoring, and evaluation strategies and achievement. 
73 | JOURNAL OF WRITING RESEARCH

Table 3. Means, standard deviations, observed range, item-total correlations, alpha, and intercorrelations between all measured variables

\begin{tabular}{|c|c|c|c|c|c|c|c|c|c|}
\hline & \multirow{2}{*}{$\begin{array}{c}\# \\
\text { items }\end{array}$} & \multirow{2}{*}{$\begin{array}{c}M \\
(S D)\end{array}$} & \multirow{2}{*}{$\begin{array}{c}\text { Observed } \\
\text { range }\end{array}$} & \multirow{2}{*}{$\begin{array}{c}\text { Range of } \\
r_{\text {it }}\end{array}$} & \multirow[t]{2}{*}{ Alpha } & \multicolumn{4}{|c|}{ Correlations } \\
\hline & & & & & & $(1)$ & $(2)$ & (3) & (4) \\
\hline \multirow[t]{2}{*}{ (1) MSK } & 20 & .62 & $0.0-1.0$ & $.20-.60$ & .77 & - & & & \\
\hline & & $(.22)$ & & & & & & & \\
\hline \multirow[t]{2}{*}{ (2) Planning } & 5 & 3.22 & $2.2-4.0$ & $.33-.47$ & .63 & $.29 * *$ & - & & \\
\hline & & $(.45)$ & & & & & & & \\
\hline \multirow[t]{2}{*}{ (3) Monitoring } & 5 & 3.31 & $2.0-4.0$ & $.46-.60$ & .74 & $.32^{* * *}$ & $.52^{* * *}$ & - & \\
\hline & & $(.48)$ & & & & & & & \\
\hline \multirow[t]{2}{*}{ (4) Evaluating } & 4 & 3.24 & $2.0-4.0$ & $.35-.48$ & .64 & $.31^{* * *}$ & $.62^{* * *}$ & $.59^{* * *}$ & - \\
\hline & & $(.50)$ & & & & & & & \\
\hline \multirow[t]{2}{*}{ (5) Achievement } & 1 & 4.76 & $3.0-6.0$ & - & - & $.37^{* * *}$ & $.26^{* *}$ & $.27^{* *}$ & $.27^{* *}$ \\
\hline & & $(.78)$ & & & & & & & \\
\hline
\end{tabular}

Note. MSK = metacognitive strategy knowledge; planning, monitoring, and evaluating as components of metacognitive strategy use; ${ }^{* * *}=p<.001 ;{ }^{* *}=p<.01 ;{ }^{*}=p<.05$.

However, the relationship between MSK and achievement $(r=.37, \mathrm{p}<.001)$ was slightly stronger than between achievement and planning, monitoring, and evaluation strategies $(r=.26$ and $r=.27)$. Altogether, the correlation between all variables were moderate.

To more fully examine the external validity of the MSK, a path model with two manifest factors (MSK, achievement) and one latent factor (metacognitive strategy use including planning, monitoring, and evaluation strategies) as mediator was deployed in Mplus 7.3 (Muthén \& Muthén, 1998-2012). To test the model fit, absolute and incremental fit indexes recommended by Schermelleh-Engel, Moosbrugger, and Müller (2003) were used: $\chi^{2} / \mathrm{df}$ ratio below 3, RMSEA value below .05, and CFI value above .95 are thought to indicate good model fit. The indices of the designed model (see Figure 2$)$ indicated that it immediately fit the data well $\left(\chi^{2}=1.752, \mathrm{df}=4\right.$, n.s., $\chi^{2} / \mathrm{df}=$ 0.44 , RMSEA $=.004, \mathrm{CFI}=1.00$ ). Therefore, no modifications were made. All metacognitive strategy use sub-scales (planning, monitoring, and evaluating) showed high significant factor loadings, indicating that the latent factor of metacognitive strategy use was well represented by the three sub-scales.

Figure 2 shows that both metacognitive components have a direct effect on achievement: MSK $(\beta=.31, p<.01)$ and metacognitive strategy use $(\beta=.35, p<.001)$ had a medium effect size on achievement. In other words, the higher the students' MSK was or the more they reported using metacognitive strategies, the higher the students' writing performance. Further, the path model revealed that MSK had a medium-sized effect $(\beta=.35, p<.001)$ on self-reported metacognitive strategy use. A small indirect effect $(\beta=.10, p<.05)$ of MSK via metacognitive strategy use on achievement was 
found. The path model also allowed investigation of the proportion of explained variance for metacognitive strategy use and achievement. The proportion of explained variance for metacognitive strategy use $\left(R^{2}=.14, p<.05\right)$ was slightly smaller than the explained variance for achievement $\left(R^{2}=.15, p<.05\right)$.

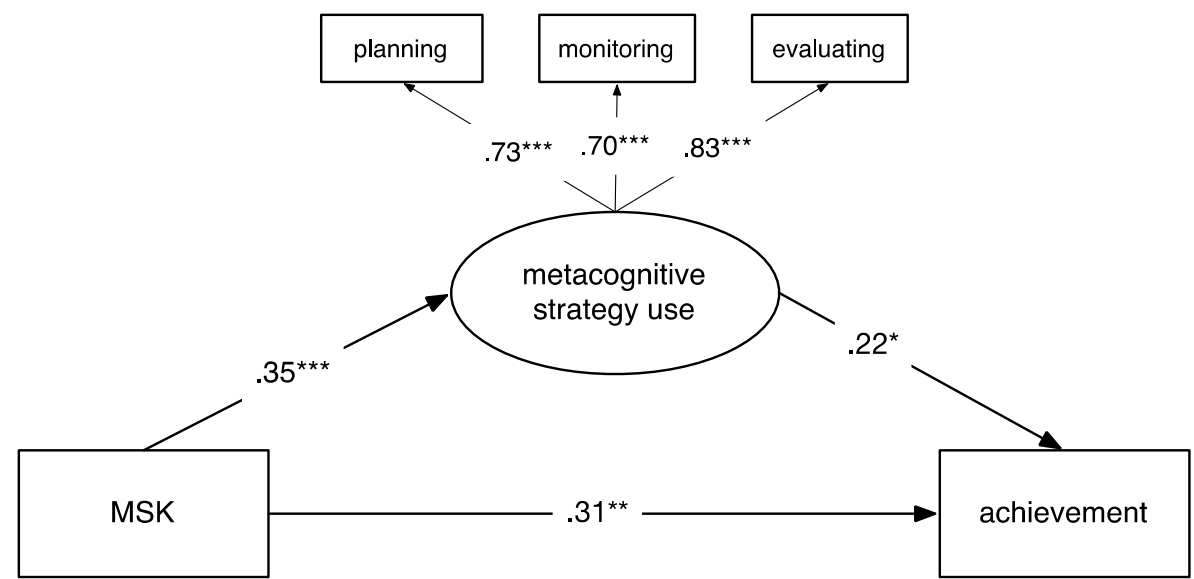

Figure 2. Path model of the relationships between metacognitive strategy knowledge, metacognitive strategy use, and achievement.

Standardized $\beta$ coefficients are shown; ${ }^{* *}=p<.001 ;{ }^{* *}=p<.01 ;^{*}=p<.05$.

As expected, students with higher MSK about academic writing showed higher performance in writing than students with lower MSK did, confirming hypothesis 1. Further, as hypothesized, MSK was positively related to the use of metacognitive strategy in writing. Results showed a moderate positive correlation between MSK and self-reported metacognitive strategy use in writing, confirming hypothesis 2 . This result showed that MSK might be an import prerequisite for the use of strategies while planning, monitoring, and evaluating an academic paper. Finally, the results confirmed the third hypothesis. Students' MSK was more strongly associated with students' writing performance than students' self-reported use of metacognitive strategies was. Moreover, results showed that MSK exerted an effect on writing performance via the use of selfreported strategy use. One possible explanation for this result is that the assessment of self-reported strategy use follows a quantitative standard (the more, the better), which is why it is unclear if those strategies were chosen adequately and applied correctly is given. In contrast, the assessment of MSK followed a qualitative standard (the higher the fit, the better) and had a clear benchmark criterion. The higher students' MSK, the more they knew which strategies to apply successfully to solve specific task challenges. Selfregulation processes need to follow a qualitative standard in order to show high 
correlation with performance (e.g., Artelt \& Schneider, 2015). In sum, the results suggest that the MSK shows good predictive validity.

\section{Overall discussion and implications}

In higher education, students must be able to write academic papers (e.g., master's theses) to successfully complete their studies. Apart from knowledge about high-quality compositions, writers also need MSK to regulate and monitor the writing process successfully and to use strategies successfully. Studies have found that skilled writers are more self-regulated than struggling writers (e.g., Harris et al., 2010). The aim of this study was to construct a new instrument that follows a qualitative standard (Wirth \& Leutner, 2008) and is at the same time relatively quick to use. Scenario-based MSK tests fulfill these requirements (e.g., Händel et al., 2013; Maag Merki et al., 2013. Here, a new scenario-based MSK test was constructed to assess students' MSK about academic writing in higher education. To examine the economic values, reliability and validate of the MSK test, several studies were conducted.

The results show that the newly developed MSK test has several features that make it distinguishable from previously constructed tests in the field of academic writing. First, owing to its multiple-choice character, the MSK test requires only a short assessment time and can hence be used for group settings and large samples and reduces administration cost. On average, the administration of the instrument takes only $2.35 \mathrm{~min}(\mathrm{SD}=0.40)$. Second, high interlinking between theoretical analyses and empirical results significantly contributed to the content validity of the MSK instrument. Based on theoretical model of self-regulated writing (e.g., Zimmerman \& Risemberg, 1997), all three writing scenarios are allocated to the three self-regulated writing phases - namely, pre-action (finding an idea, planning), action (monitoring the writing process), and post-action (evaluating the writing process). In addition, the pre-study made it possible to identify several strategies for all three writing phases that are close to students' actual strategic behavior; those strategies are listed as strategy alternatives, which are more or less useful regarding the writing-scenario-specific challenges. Third, the MSK instrument has a qualitative evaluation standard. For this, the superiority or inferiority of one strategy to another strategy was evaluated by experts' ratings. In Study 1 a high level of agreement between the experts on the pair comparisons used was found. These expert ratings provide a clear benchmark for evaluating the MSK score. This is important, as self-regulation processes need to fulfill certain standards in order to show high correlation with performance (e.g., Artelt \& Schneider, 2015). In line with this, the results of Study 2 confirm that MSK is a stronger predicator of writing achievement than metacognitive strategy use is. Nevertheless, self-reported metacognitive strategy use is also positively correlated with writing achievement.

Further, the results of Study 2 show that MSK is positively related to self-reported metacognitive strategy use. Students who demonstrate high MSK are more likely to report higher frequency of metacognitive strategy use. Note that, this does not mean 
that these strategies will be used when the writing situation calls for it, as other circumstances (e.g., motivation, learning goals, task difficulty) might influence whether certain strategies are applied or not (Artelt \& Schneider, 2015). However, in a different study we found that MSK is an important prerequisite of metacognitive strategy use (Karlen, 2015). All together they are empirical evidence in support of the value of the MSK measure. Finally, the results of Study 2 show that overall internal consistency of the MSK test is satisfactory. Moreover, the pair comparisons differ appropriately regarding their difficulty. Thus, the MSK test shows appropriate difficulty level for the sample of university students.

\subsection{Limitations}

Several aspects limit this study. First, the MSK test is limited to the genre of academic writing and to the writing scenarios presented. Therefore, the content-specific MSK about academic writing might possibly not be applicable to other writing domains. Moreover, the genre of academic writing is to a certain degree discipline dependent (Elton, 2010). This limits the generalizability of the results. It is conceivable that MSK and strategy use may vary across content areas and writing domains. Greene et al. (2015) found that self-regulated learning processing is to a certain degree domainspecific. Further studies will have to examine how far the assessed MSK about academic writing can be applied to other writing genres and other academic writing disciplines.

Second, even though high content validity is reached through theoretical and empirical validation of the selected scenarios and strategies, due to timing considerations the MSK test is restricted to the three scenarios selected and the strategies listed. The strategies and scenarios are representative of the context of academic writing, but it could be interesting to assess further aspects of self-regulated academic writing by adding additional writing scenarios and strategies. This could provide further information about students' MSK about academic writing. However, it should be kept in mind that this procedure would increase the time required to fill out the MSK test.

Third, as a self-report questionnaire was used, it was not possible to assess students' actual metacognitive regulation behavior during the writing process. Moreover, the assessment of strategy use by questionnaire does not provide any information about the quality of strategy use (Artelt \& Schneider, 2015). For this very reason, the validity of self-reported strategy use has been questioned in the last few years. Nonetheless, Berger and Karabenick (2016) showed that it is possible to increase construct validity of selfreported strategy use by targeting the items to the specific situation and topic.

Finally, due to the specific sample of students studying education science, the results might have limited generalizability to other groups of students (e.g., students in natural sciences programs). For example, in education science the competence of academic writing is highly important for being a successful student (in contrast to be 
able to run experiments or doing laboratory work) and students must be dealing with learning theories (i.e., self-regulated learning) as part of the curriculum. Moreover, educational science students are mainly women. Therefore, it is also recommended to verify the results of this study with a sample of students with a more balanced gender composition.

\subsection{Practical implications and future directions}

This instrument may be a valid diagnostic tool to be used by teachers and practitioners to assess students' MSK. To foster and support students' academic writing, it is highly important to have information on students' MSK. The MSK test could help teachers to find out whether their students lack MSK about academic writing. Having this information, teachers could provide specific instructions that help students to optimize the regulation and monitoring of their writing process and improve their writing quality. To foster students' MSK about academic writing, the explicit teaching of strategies to successfully regulate one's own writing process should play an important role (Wischgoll, 2016). Further, if students are to develop knowledge on the use of different strategies and their relative strengths and weaknesses, they need to encounter multiple experiences with their use and should be supported in reflecting upon their strategic behavior.

For researchers, it might be interesting to use the MSK test for pre-post intervention studies to measure achieved and sustained differences. The instrument developed here could also be used to generate further information on the development of MSK in relation to the development of academic writing competencies. It might also be used in conjunction with other instruments to examine the connection between the quality of strategy use and MSK in academic writing. Because the MSK test developed here is quick to use, it can be easily combined with other instruments (e.g., learning journals). This could help to gain further insights into students' successful or unsuccessful selfregulation of their academic writing process and the connection between MSK and other aspects of self-regulated writing (e.g., motivation). In addition to the assessment of MSK, it would be interesting to assess students' knowledge about attributes and structure of academic writing. Besides MSK, knowledge about characteristics of highquality genre-specific compositions plays an important role in successful writing (Harris et al., 2010). Gaining further insights in into the interplay between these knowledge types could contribute towards a better understanding of why some writers struggle.

\section{Acknowledgements}

I thank Silke Hertel for her input on the development of the new MSK test. I am also grateful to Francesca Suter for her help with the data collection of the pre-study. I would also like to say thank you to the experts for their valuable ratings and their comments on an earlier version of the MSK test. 


\section{References}

Artelt, C., Neuenhaus, N., Lingel, K., \& Schneider, W. (2012). Entwicklung und wechselseitige Effekte von metakognitiven und bereichsspezifischen Wissenskomponenten in der Sekundarstufe [Development and reciprocal effects of metacognitive and domain-specific knowledge in high-school]. Psychologische Rundschau, 63(1), 18-25. doi:10.1026/00333042/a000106

Artelt, C., \& Schneider, W. (2015). Cross-country generalizability of the role of metacognitive knowledge for students' strategy use and reading competence. Teachers College Record, $117(1), 1-32$.

Beauvais, C., Olive, T., \& Passerault, J.-M. (2011). Why are some texts good and others not? Relationship between text quality and management of the writing processes. Journal of Educational Psychology, 103(2), 415-428. doi: 10.1177/0741088313491692

Berger, J.-L., \& Karabenick, S. A. (2016). Construct validity of self-reported metacognitive learning strategies. Educational Assessment, 21(1), 19-33. doi:10.1080/10627197.2015.1127751

Borkowski, J. G., \& Turner, L. A. (1990). Transsituational characteristics of metacognition. In W. Schneider \& F. E. Weinert (Eds.), Interactions among aptitudes, strategies, and knowledge in cognitive performance (pp. 159-176). New York, NY: Springer.

Brown, A. L. (1987). Metacognition, executive control, self•regulation, and other more mysterious mechanisms. In F. E. Weinert \& R. H. Kluwe (Eds.), Metacognition, motivation, and understanding (pp. 65-116). Hillsdale, NJ: Erlbaum.

Ebel, R. L. (1979). Essentials of educational measurement. Engelwood Cliffs, NJ: Prentice-Hall.

Elton, L. (2010). Academic writing and tacit knowledge. Teaching in Higher Education, 15(2), 151 160. doi:10.1080/13562511003619979

Englert, C. S., Raphael, T. E., Fear, K. L., \& Anderson, L. M. (1988). Students' metacognitive knowledge about how to write informational texts. Learning Disability Quarterly, 11(1), 18-46. doi:10.2307/1511035

Ferrari, M., Bouffard, T., \& Rainville, L. (1998). What makes a good writer? Differences in good and poor writers' self-regulation of writing. Instructional Science, 26(6), 473-488. doi:10.1023/A:1003202412203

Flavell, J. H. (1979). Metacognition and cognitive monitoring: A new area of cognitivedevelopment inquiry. American Psychologist, 34(10), 906-911. doi: 10.1037/0003066X.34.10.906

Flavell, J. H., Miller, P. H., \& Miller, S. A. (2002). Cognitive development (4th ed.). Upper Saddle River, NJ: Pearson Education.

Graham, S., \& Harris, K. R. (2000). The role of self-regulation and transcription skills in writing and writing development. Educational Psychologist, 35(1), 3-12. doi:10.1207/s15326985ep3501_2

Graham, S., Schwartz, S. S., \& MacArthur, C. A. (1993). Knowledge of writing and the composing process, attitude toward writing, and self-efficacy for students with and without learning disabilities. Journal of Learning Disabilities, 26(4), 237-249. doi:10.1177/0022219493026 00404

Greene, J. A., Bolick, C. M., Jackson, W. P., Caprino, A. M., Oswald, C., \& McVea, M. (2015). Domain-specificity of self-regulated learning processing in science and history. Contemporary Educational Psychology, 42, 111-128. doi:10.1016/j.cedpsych.2015.06.001

Hacker, D. J., Keener, M. C., \& Kircher, J. C. (2009). Writing is applied metacognition. In D. J. Hacker, J. Dunlosky, \& A. C. Graesser (Eds.), Handbook of metacognition in education (pp. 154-172). New York, NY: Routledge.

Hammann, L. (2005). Self-regulation in academic writing tasks. International Journal of Teaching and Learning in Higher Education, 17(1), 15-26.

Händel, M., Artelt, C., \& Weinert, S. (2013). Assessing metacognitive knowledge: Development and evaluation of a test instrument. Journal for Educational Research Online, 5(2), 162-188. 


\section{9 | JOURNAL OF WRITING RESEARCH}

Händel, M., Lockl, K., Heydrich, J., Weinert, S., \& Artelt, C. (2014). Assessment of metacognitive knowledge in students with special educational needs. Metacognition and Learning. doi:10.1007/s11409-014-9119-x

Harris, K. R., Santangelo, T., \& Graham, S. (2010). Metacognition and strategies instruction in writing. In H. S. Waters \& W. Schneider (Eds.), Metacognition, strategy use, and instruction (pp. 226-256). New York, NY: Guilford Press.

Hayes, J. R. (1996). A new framework for understanding cognition and affect in writing. In C. M. Levy \& S. Ransdell (Eds.), The science of writing: Theories, methods, individual differences, and applications (pp. 1-27). Mahwah, NJ: Lawrence Erlbaum.

Kaplan, A., Lichtinger, E., \& Gorodetsky, M. (2009). Achievement goal orientations and selfregulation in writing: An integrative perspective. Journal of Educational Psychology, 101(1), 51-69. doi:10.1037/a0013200

Karlen, Y. (2015). Nutzungshäufigkeit von Lernstrategien und metakognitives Strategiewissen in der Oberstufe des Gymnasiums: Entwicklung und Zusammenhänge [Frequency of strategy use and metacognitive strategy knowledge at the upper secondary school level: Development and relations]. Zeitschrift für Bildungsforschung, 5(2), 159-175. doi:10.1007/s35834-015-0123-2

Karlen, Y., Maag Merki, K., \& Ramseier, E. (2014). The effect of individual differences in the development of metacognitive strategy knowledge. Instructional Science, 42(5), 777-794. doi:10.1007/s11251-014-9314-9

Kreutzer, M. A., Leonard, C., \& Flavell, J. H. (1975). An interview study of children's knowledge about memory. Monographs of the Society for Research in Child Development, 40, 1-60.

Lin, S.-J. C., Monroe, B. W., \& Troia, G. A. (2007). Development of writing knowledge in grades 2-8: A comparison of typically developing writers and their struggling peers. Reading \& Writing Quarterly, 23(3), 207-230. doi:10.1080/10573560701277542

Maag Merki, K., Ramseier, E., \& Karlen, Y. (2013). Reliability and validity analyses of a newly developed test to assess learning strategy knowledge. Journal of Cognitive Education and Psychology, 12(3), 391-408. doi:10.1891/1945-8959.12.3.391

McCutchen, D. (2006). Cognitive factors in the development of children's writing. In C. A. MacArthur, S. Graham, \& J. Fitzgerald (Eds.), Handbook of writing research (pp. 115-130). New York, NY: Guilford Press.

Muthén, L. K., \& Muthén, B. O. (1998-2012). Mplus user's guide. (7th ed.). Los Angeles, CA: Muthén \& Muthén.

Negretti, R. (2012). Metacognition in student academic writing: A longitudinal study of metacognitive awareness and its relation to task perception, self-regulation, and evaluation of performance. Written Communication, 29(2), 142-179. doi:10.1177/0741088312438529

Nelson, T. O., \& Narens, L. (1994). Why investigate metacognition? In J. Metcalfe \& A. P. Shimamura (Eds.), Metacognition: Knowing about knowing (pp. 1-25). Cambridge, MA: MIT Press.

Olinghouse, N. G., \& Graham, S. (2009). The relationship between the discourse knowledge and the writing performance of elementary-grade students. Journal of Educational Psychology, 101(1), 37-50. doi:10.1037/a0013248

Paris, S. G., Lipson, M. Y., \& Wixson, K. K. (1983). Becoming a strategic reader. Contemporary Educational Psychology, 8(3), 293-316. doi:10.1016/0361-476x(83)90018-8

Paris, S. G., \& Winograd, P. (1990). Promoting metacognition and motivation of exceptional children. Remedial and Special Education, 11(6), 7-15.

Pintrich, P. R., Smith, D. A. F., Garcia, T., \& McKeachie, W. J. (1993). Reliability and predictive validity of the motivated strategies for learning questionnaire (MSLQ). Educational and Psychological Measurement, 53(3), 801-813.

Saddler, B., \& Graham, S. (2007). The relationship between writing knowledge and writing performance among more and less skilled writers. Reading \& Writing Quarterly, 23(3), 231247. doi:10.1080/10573560701277575 
Schermelleh-Engel, K., Moosbrugger, H., \& Müller, H. (2003). Evaluating the fit of structural equation models: Tests of significance and descriptive goodness-of-fit measures. Methods of Psychological Research Online, 8(2), 23-74.

Schraw, G., \& Dennison, R. S. (1994). Assessing metacognitive awareness. Contemporary Educational Psychology, 19(4), 460-475. doi:10.1006/Ceps.1994.1033

Schraw, G., \& Moshman, D. (1995). Metacognitive theories. Educational Psychology Review, 7(4), 351-371. doi 10.1007/Bf02212307

Swanson, H. L. (1990). Influence of metacognitive knowledge and aptitude on problem-solving. Journal of Educational Psychology, 82(2), 306-314. doi:10.1037/0022-0663.82.2.306

Veenman, M. V. J., Hout-Wolters, B. H. A. M., \& Afflerbach, P. (2006). Metacognition and learning: Conceptual and methodological considerations. Metacognition and Learning, 1(1), 3 14. doi:10.1007/s11409-006-6893-0

Wirth, J., \& Leutner, D. (2008). Self-regulated learning as a competence. Implications of theoretical models for assessment methodes. Zeitschrift für Psychologie, 216(2), 102-110. doi:10.1027/0044-3409.216.2.102

Wirtz, M., \& Caspar, F. (2002). Beurteilerübereinstimmung und Beurteilerreliabilität [Rater agreement and interrater reliability]. Göttingen, Germany: Hogrefe.

Wischgoll, A. (2016). Combined training of one cognitive and one metacognitive strategy improves academic writing skills. Frontiers in Psychology, 7, 187. doi:10.3389/fpsyg. 2016.00187

Zimmerman, B. J., \& Risemberg, R. (1997). Becoming a self-regulated writer: A social cognitive perspective. Contemporary Educational Psychology, 22(1), 73-101. doi:10.1006/Ceps.1997. 0919 
81 | JOURNAL OF WRITING RESEARCH

\section{Appendix A:}

\section{German version of the MSK test about academic writing (MSK-AW-D test)}

\section{Einleitung}

Wir haben im Vorfeld dieser Studie Studierende gefragt, wie sie anspruchsvolle wissenschaftliche Texte an der Universität realisieren. Diese Antworten haben wir auf den nachfolgenden Seiten zusammengetragen. Bestimmen Sie die Nützlichkeit der einzelnen Vorgehensweisen auf einer Skala von 1 (= überhaupt nicht nützlich) bis 6 (= sehr nützlich) für die jeweilige Lernsituation.

\section{Szenario 1}

Bevor eine Person mit dem Schreiben der Arbeit beginnt, möchte sie sich darauf vorbereiten. Für wie nützlich halten Sie die folgenden Vorgehensweisen in der Phase vor dem Schreiben.

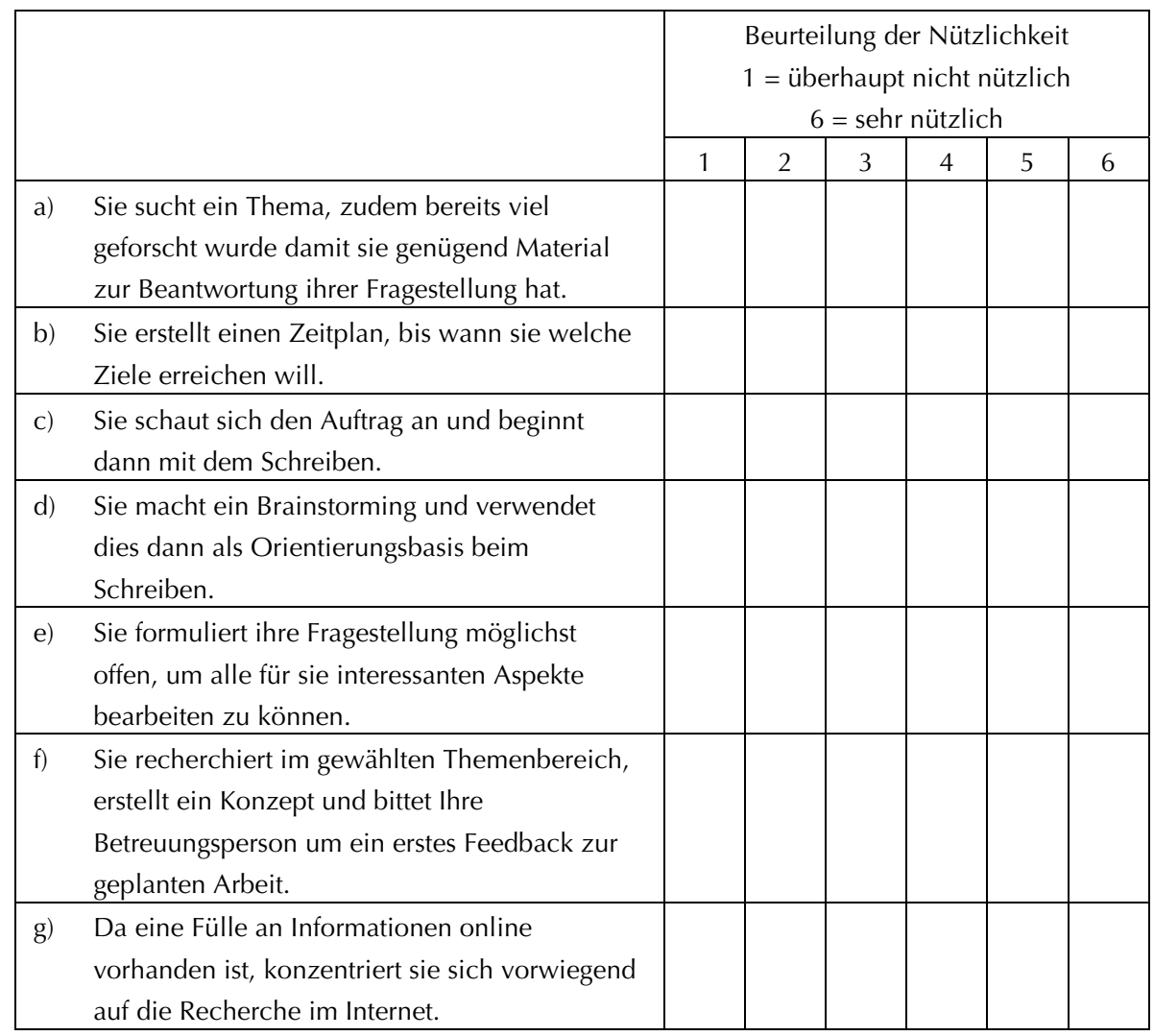


h) Sie erstellt ein Mindmap des bereits vorhandenen Wissens und ergänzt dies allenfalls mit weiteren Informationen aus der Literatur.

Szenario 2

Stellen Sie sich vor, dass eine Person während des Schreibens ihren Arbeitsprozess überwachen möchte. Für wie nützlich halten Sie die folgenden Vorgehensweisen?

\begin{tabular}{|c|c|c|c|c|c|c|c|}
\hline & \multicolumn{6}{|c|}{$\begin{array}{l}\text { Beurteilung der Nützlichkeit } \\
\begin{array}{l}1=\text { überhaupt nicht nützlich } \\
6=\text { sehr nützlich }\end{array}\end{array}$} \\
\hline & & 1 & 2 & 3 & 4 & 5 & 6 \\
\hline a) & $\begin{array}{l}\text { Sie orientiert sich während des Schreibens an der } \\
\text { gefundenen Literatur und an ihren Notizen. }\end{array}$ & & & & & & \\
\hline b) & $\begin{array}{l}\text { Sie platziert ihre Fragestellung sichtbar am } \\
\text { Arbeitsplatz, damit sie den roten Faden während } \\
\text { des Schreibens nicht verliert. }\end{array}$ & & & & & & \\
\hline C) & $\begin{array}{l}\text { Während des Schreibens gleicht sie das } \\
\text { Geschriebene fortlaufend mit der } \\
\text { Aufgabenstellung ab. }\end{array}$ & & & & & & \\
\hline d) & $\begin{array}{l}\text { Sie erwägt während des Schreibens stets ihre im } \\
\text { Voraus definierte Argumentation. }\end{array}$ & & & & & & \\
\hline e) & $\begin{array}{l}\text { Sie orientiert sich während des Schreibens stets } \\
\text { an die bereits verfasste Einleitung. }\end{array}$ & & & & & & \\
\hline f) & $\begin{array}{l}\text { Während des Schreibens liest sie ab und zu } \\
\text { jemandem eine Textstelle vor, um die } \\
\text { Verständlichkeit zu überprüfen. }\end{array}$ & & & & & & \\
\hline
\end{tabular}

Szenario 3

Stellen Sie sich vor, dass eine Person nun ihren wissenschaftlichen Text überarbeiten möchte. Für wie nützlich halten Sie die folgenden Vorgehensweisen?

\begin{tabular}{|c|c|c|c|c|c|c|c|}
\hline & & \multicolumn{6}{|c|}{$\begin{array}{l}\text { Beurteilung der Nützlichkeit } \\
\begin{array}{l}1=\text { überhaupt nicht nützlich } \\
6=\text { sehr nützlich }\end{array}\end{array}$} \\
\hline & & 1 & 2 & 3 & 4 & 5 & 6 \\
\hline a) & $\begin{array}{l}\text { Sie überarbeitet geschriebene Sätze fortlaufend } \\
\text { und achtet dabei gleichzeitig auf inhaltliche und } \\
\text { sprachliche Optimierungen. }\end{array}$ & & & & & & \\
\hline
\end{tabular}


83 | JOURNAL OF WRITING RESEARCH

b) Nachdem sie den Text verfasst hat, überarbeitet sie die Stellen, die ihrer Meinung nach noch nicht gelungen sind.

c) Bei der inhaltlichen Überarbeitung lässt sie ihre Argumentation unverändert, um den Text schlüssig zu halten.

d) Sie vergewissert sich, dass der Hauptteil der Arbeit mit der anfangs verfassten Einleitung übereinstimmt.

e) Am Ende des Schreibprozesses gibt sie die Arbeit jemanden zum Gegenlesen, aufgrund des erhaltenen Feedbacks überarbeitet sie die Arbeit.

f) Sie wartet ein paar Tage, druckt den Text dann aus und überarbeitet ihn inhaltlich und sprachlich. 


\section{Appendix B:}

\section{English version of the MSK test about academic writing (MSK-AW-E test)}

\section{Introduction}

Prior to this study we asked students how they write demanding academic texts at the university. Their answers are compiled on the pages below. Please rate the usefulness/helpfulness of the different ways of proceeding when writing a paper on a scale from 1 (not useful at all) to 6 (very useful) for the learning scenarios below.

Scenario 1

Before a person begins writing the paper, she will want to prepare to write. How useful/helpful do you rate the following ways of proceeding in the preliminary stage before writing?

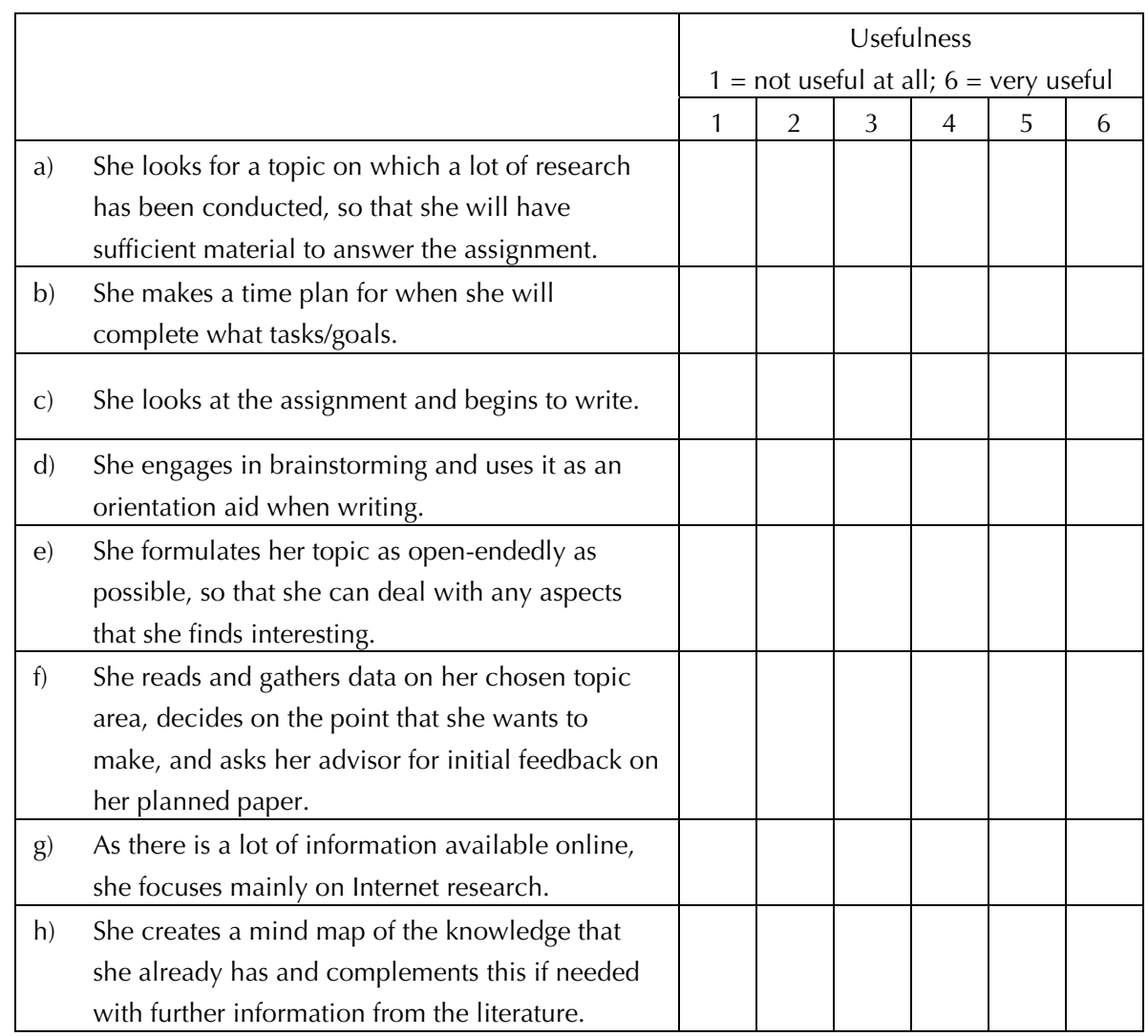


85 | JOURNAL OF WRITING RESEARCH

Scenario 2

Imagine that a person wants to monitor her work process while writing a paper. How useful do you rate the following ways of proceeding?

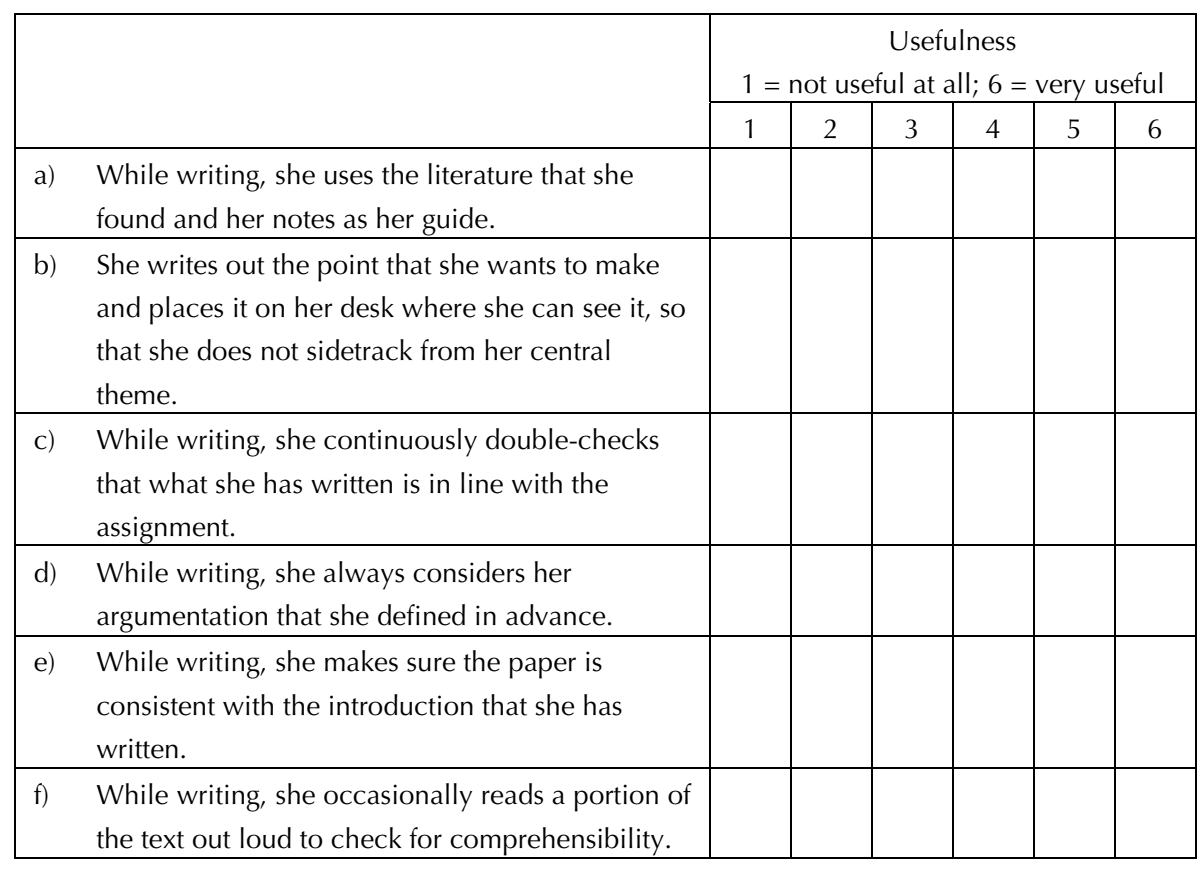

Scenario 3

Imagine that a person now wants to revise her paper. How useful do you rate the following ways of proceeding?

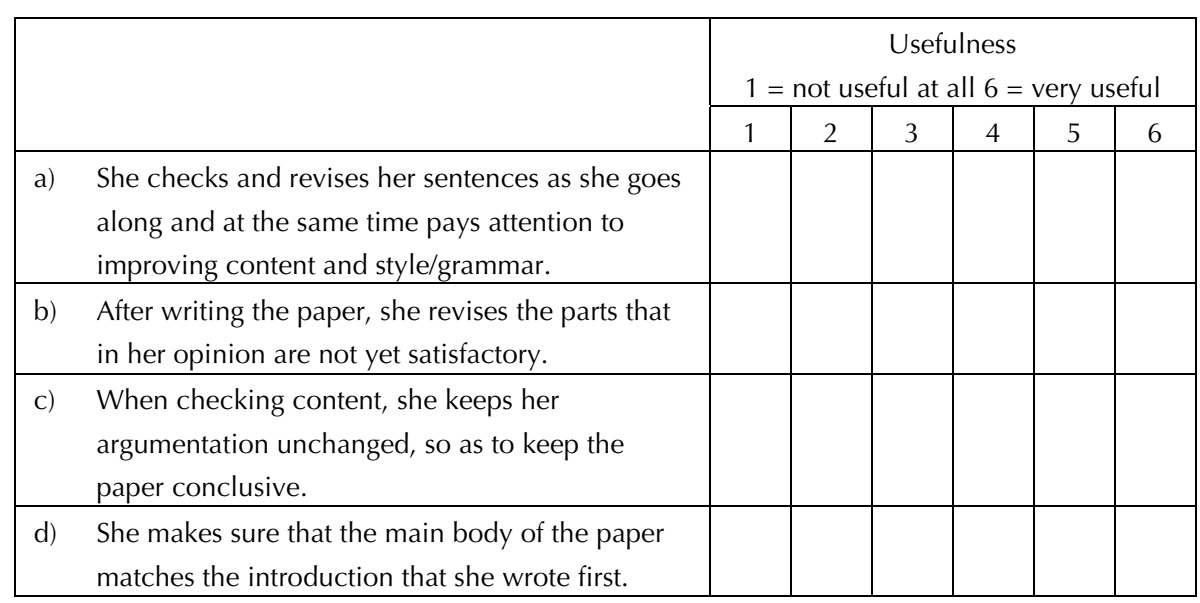


Karlen - Metacognitive Strategy KNOWLEdge about ACAdemic Writing | 86

e) At the end of the writing process, she has someone else read her paper and revises it based on their feedback.

f) She waits a few days and then prints out her paper and checks content and style/grammar. 